\title{
Implementation of an Intelligent Door Bell System Using Internet of Things
}

\author{
P. Ratna Kamala ${ }^{1}$, P. Pavan Kumar ${ }^{2}$ and A. Anish ${ }^{3}$ \\ ${ }^{1}$ Professor, ${ }^{2}$ Assistant Professor, ${ }^{3}$ UG Student, \\ ${ }^{1,2 \& 3}$ Department of Electronics and Communication Engineering, SIETK, Puttur, Andhra Pradesh, India \\ E-Mail: ratnapkamala@gmail.com,pavan.android961@gmail.com, amanishmadhu@gmail.com
}

\begin{abstract}
Security has become the most important issue in this modernised world. Especially in cases where nobody is available at home, residences dwelled with old age people and the residences of working citizens needs security as the residents and things within the home has become a severe issue of concern as many intruders are concentrating on these type of residences for easy way of earning. To eradicate such activities by the intruders to certain extent, several strategies and systems were developed and been into market. Most of the proposed smart home systems try to bring solutions for security problem, at the cost of usage of numerous sensor devices. Also threats to these security solutions are also increasing as technology is developing. Internet of Things (IoT), a giant network of connected devices is the latest technology being used everywhere. With the increasing threats to security issues, it is necessary to use such new technologies to achieve the same with increased security. This paper presents a real time Image based intelligent door system for home security that uses a pi camera. This is an efficient approach in providing security and thereby a reliable embedded system device developed utilising the technology to meet the complex and challenging tasks. If a person clicks the door bell, picture of the person is captured and the image is sent to the owner through SMS and e-mail. Owner of the house can respond by opening the door if he is available in the house. If he is out of the house, a message is sent back to the person in the form of an audible voice and is made audible through a speaker. Proposed system offers several advantages in providing safety and security in terms of visualization and identification of people who visits the home.

Keywords: Security, Internet of Things, Raspberry Pi-3, PiCamera, Wi-Fi Technology, Embedded Systems
\end{abstract}

\section{INTRODUCTION}

Internet of Things (IOT) is the network of "things" which are connected to a common network path in order to communicate, exchange data or control each other. Network path can be interconnected with the "things" that may be embedded software, hardware or any sensor. It refers to the state where the things will have more data and information associated with them and has an ability to communicate, produce new information and become integral part of the free world wide web. It not only features internet connectivity but also features cloud and data management, security management and all other fields concerned with the era of internet. Over the world, IOT and M2M (Machine to Machine Interpersonal Communication) technologies developed for smart home system has become much popular these days. With increasing safety and security issues, the use of smart door system increased consistently with the advent of security related electronics, such as digital door locks, advanced video conversation devices, and wireless home security networks, etc. Many smart systems are proposed to provide safety and security at homes and offices.

In the proposed system, to provide home security two different techniques are implemented. One is to use image technology to see the front door in real time even if none is available at home and another is to provide communication between the door system and smart phone device. By connecting the smart door system with the mobile phone through the cellular network, the owner of the house have several opportunities such as controlling the house, getting instant images, receiving and sending message for alerting the owner. Supported mobile communication and safety powered multifunctional smart door system has aided in achieving intense Security.

This system will allow visual communication between visitors and owners of the house. Features such as video camera system, instant message notification, SMS / MMS notification and dual audio / single sided process are provided with video phone. In addition, cloud storage of image data with a high resolution will be provided using this system.

\section{METHODOLOGY}

This system comprises of two stages: 1 . Smart system using phone management and 2. Foreign individual identification i.e., detection of person/ people. It is an intelligent door system with camera-based identification. Main facilities available in this project are:

1. It provides Administration Level-Owner management.

2. It sends details of every person which come in front of door via notification.

3. This system is very useful for handicapped and physically disabled persons.

4. Image capturing.

5. If human rings the bell, then only system is activated.

6. If owner is not there, then image and info will be forwarded to owner's number. 
The Block diagram of the proposed system is shown in Fig. 1.

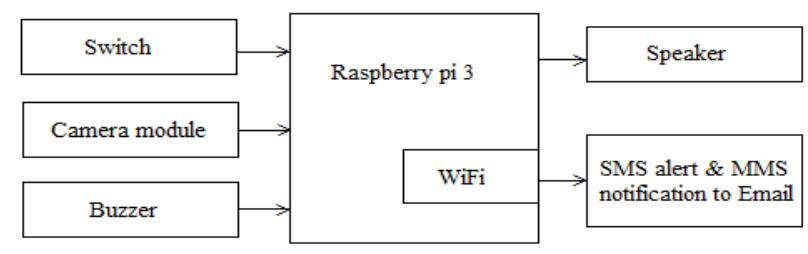

Host side

\begin{tabular}{|l|}
\hline Smart phone \\
\hline WiFi (or) Internet \\
\hline $\begin{array}{l}\text { Visitor image to } \\
\text { Email \& Reply to } \\
\text { rasperry pi system } \\
\text { through Email }\end{array}$ \\
\hline
\end{tabular}

\section{$\underline{\text { Recipient side }}$}

Fig. 1 Block diagram of proposed smart door bell

The proposed smart door system shown in Fig. 1 provides security, early warning and communication to the residents and thereby preventing potential security problems. This system developed with new features will distinguish itself from existing systems.

Fig. 2 shows the flow chart of proposed project. Interfacing Raspberry pi to switch, pi-camera, speaker \&Buzzer is done and when calling Bell is pressed series of actions will be performed to detect the person or visitor before the doorsteps. The system is idle until the button is pressed. If button is pressed then pi-camera captures the image of the visitor and alerts the owner by sending SMS alert along with the image of the visitor through email. After sending SMS \&e-mail alerts the system and waits for the owner's reply. After receiving the reply from owner through e-mail in the form of text, the raspberry pi converts that text into speech and gives an audio output through speaker.

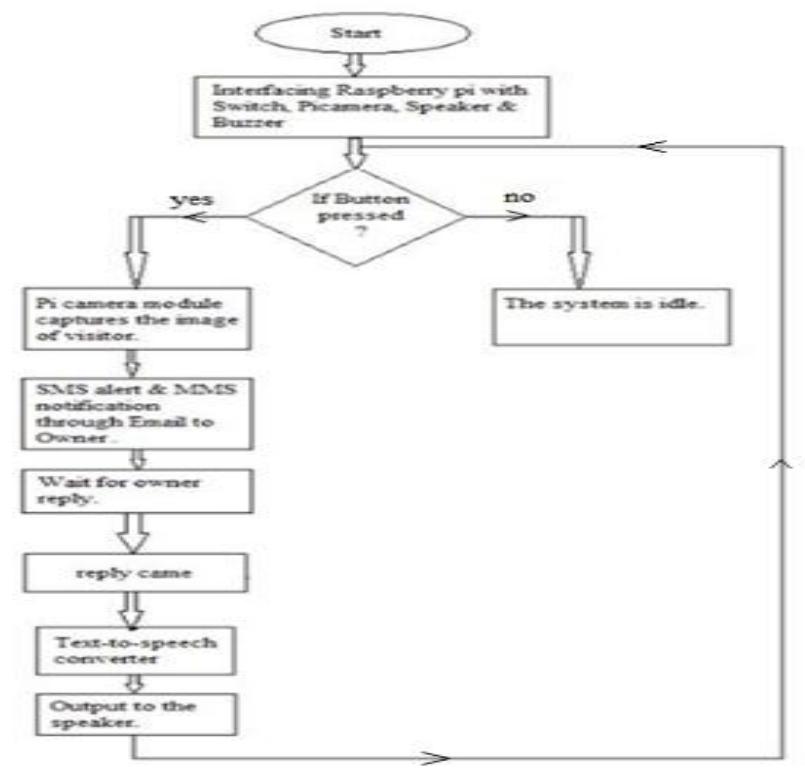

Fig. 2 Flow chart of proposed system

\section{TECHNICAL DETAILS}

Hardware for the proposed system includes: Raspberry pi, Camera module, Speakers and Buzzer. In the proposed system Raspberry pi 3 is used. Fig. 3 shows the picture of Raspberry pi and Fig.4 shows the Pi-Camera Module. It's a very small PCB on which exists an Omni vision OV5647 camera module. It connects to raspberry Pi using a $15 \mathrm{~cm} 15$ way ribbon connector.

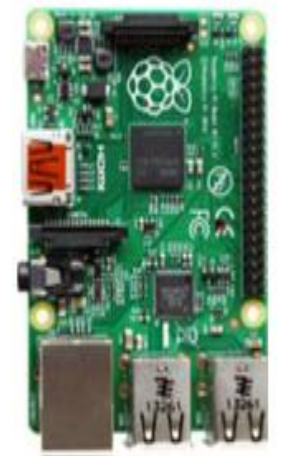

Fig. 3 Raspberry Pi 3,

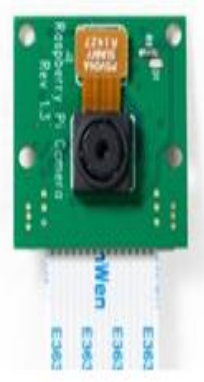

Fig. 4 Raspberry Pi camera Module
The camera module connects to the Raspberry Pi board via the CSI connector designed specifically for interfacing to cameras. The CSI bus is capable of extremely high data rates, and it exclusively carries pixel data to the BCM2837 processor. For input and connectivity other devices were used besides Raspberry. Speakers were used to convey message to the visitor. The message sent by owner to the raspberry pi system through email is converted into voice by text-to-speech mechanism. An electric buzzer is a loudspeaker that uses the piezoelectric effect for generating sound. Interfacing of speakers with raspberry pi is shown in Fig.5.The buzzer module used in this system is shown in Fig. 6.
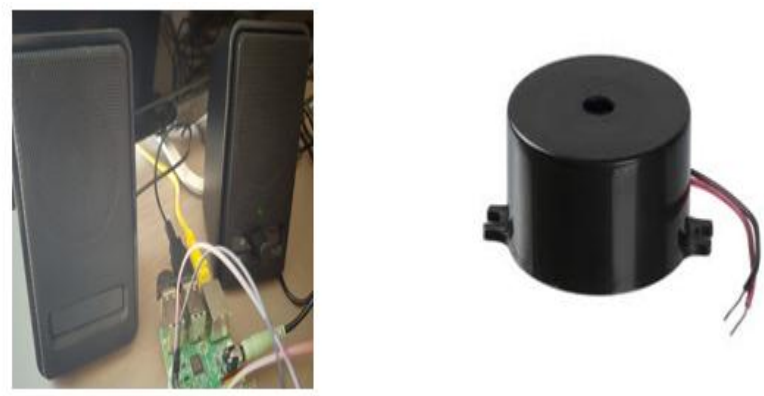

Fig. 5 Raspberry Pi interfacing with speakers, Fig. 6 Buzzer Module

\section{RESULTS AND DISCUSSION}

The final prototype of the proposed system is shown in Fig.7.Once the visitor presses the button as shown in Fig.8, raspberry pi gets activated and alerts the owner. At first, it says "Please wait for the reply from owner" from the speakers connected to it. This is shown in Fig.9. Then it sends the SMS alert and image of the visitor to owner's email by using picamera module as shown in Fig.10 \&Fig.11. 


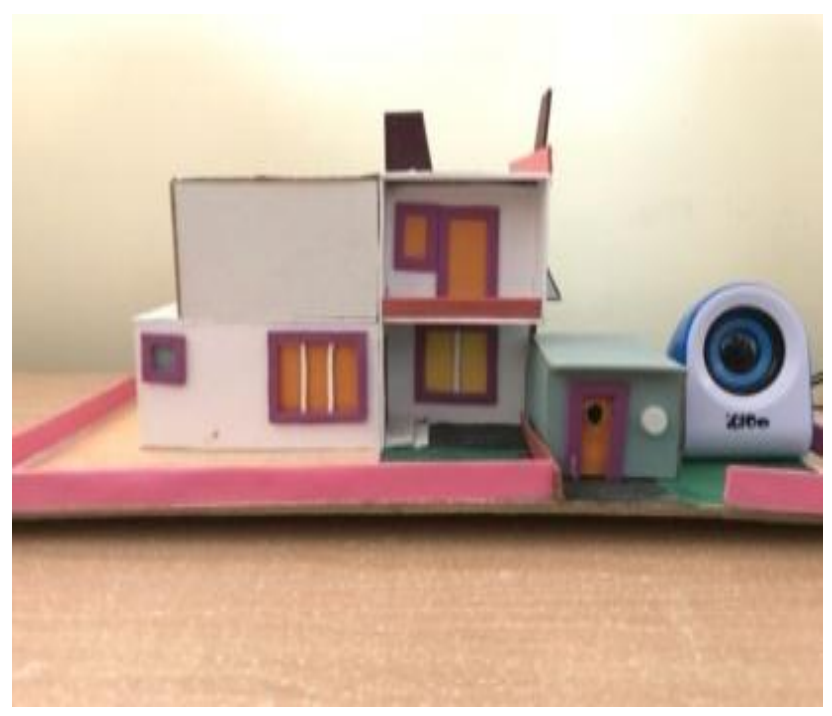

Fig. 7 Prototype for proposed system

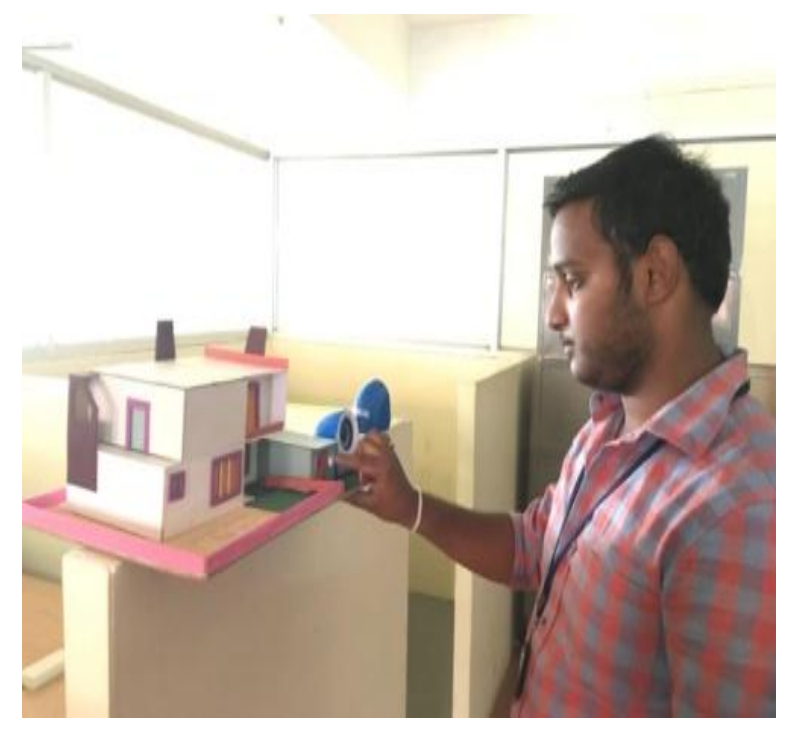

Fig. 8 Visitor pressing the Door bell

\section{*Python 2.7.13 Shell"}

File Eoblit Shell Debug Qoptions Window Help

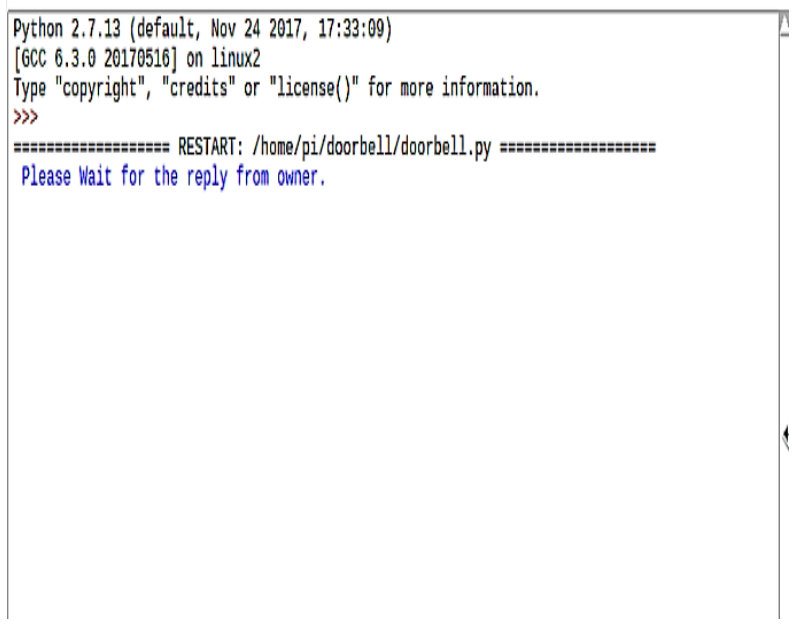

Fig. 9 Speaker's output once the visitor rings the bell

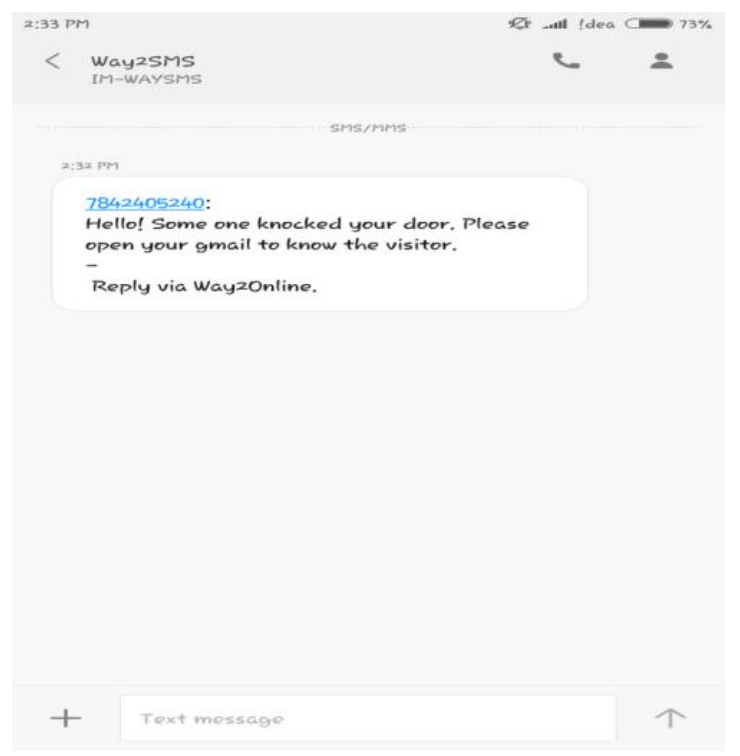

Fig. 10 SMS alert sent to the owner

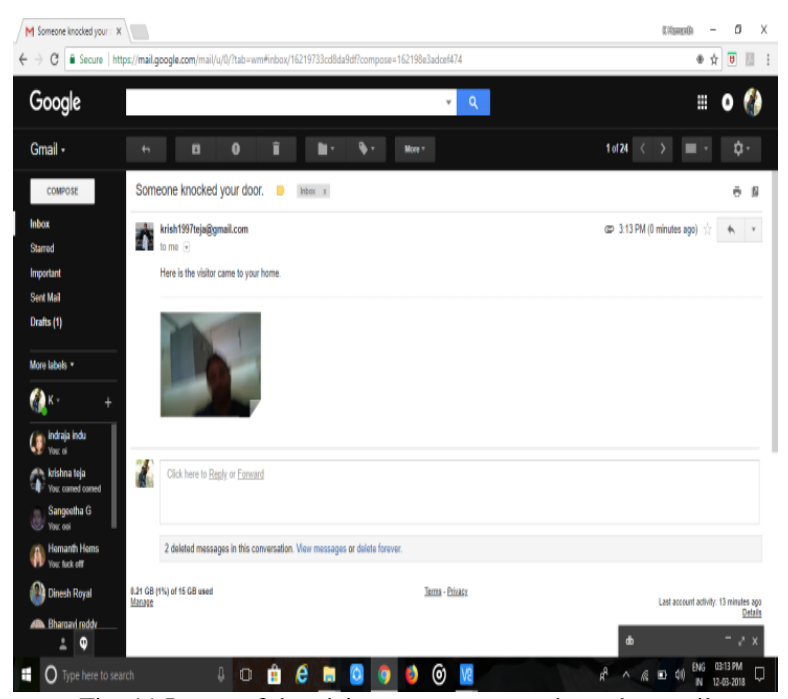

Fig. 11 Image of the visitor sent to owner through e-mail

Once the owner receives the e-mail and is aware of the visitor, he can give reply as shown in Fig.12.

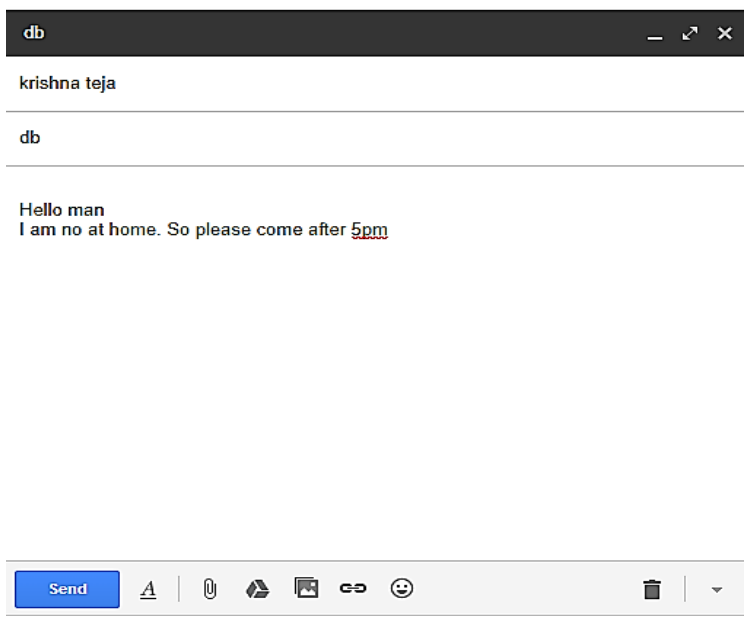

Fig. 12 Owner's reply to the visitor 
Whatever the message is typed, it gets converted into speech by Raspberry pi and is made audible to the visitor through the speakers connected to raspberry pi.

\section{CONCLUSION}

This paper gives basic idea of how to remotely monitor the house and protect it from threats by intruders. It will work when the bell rings at the door and this will act as a trigger to the camera and the camera will capture the image of the person standing in front of the door. The image of the visitor will be shown to the registered user who is away from home through e-mail and sms alert to check the mail is sent to phone. Then identification of the person is done and through e-mail he can reply back to the person standing in front of the door. The experimental results indicate that the proposed system may provide a consistent support and assistance for safe and secure life.

\section{REFERENCES}

[1] R. J. Robles, T.-h. Kim, D. Cook, and S. Das, "A review on security in smart home development," International Journal of Advanced Science and Technology, Vol. 15, 2010.

[2] JayashriBangalil, A. Shaligram, "Design and Implementation of Security Systems for Smart Home based on GSM technology", International Journal of Smart Home, Vol. 7, No. 6, pp. 201-208, 2013.
[3] A. H. Mohammad, "Of electronic doorbell with counter and display," Ph.D. dissertation, 2009.

[4] H. V. Shah, G. Y. Tsao, A. L. Arizpe, and A. S. Oztaskin, "Doorbell mechanism using protection domains," Dec. 14 2010, us Patent 7,853,957.

[5] Raqibull Hasan et al., "Microcontroller Based Home Security System with GSM Technology", Open Journal of Safety Science and Technology, Vol. 5, pp. 55-62, June 2015.

[6] M. Senagala, "Rethinking smart architecture: Some strategic design frameworks," International Journal of Architectural Computing, Vol. 4, No. 3, pp. 33-46, 2006.

[7] AjinkyaKawale, "Fingerprint based locking system", International Journal of Scientific \& Engineering Research, Vol. 4, No. 5, May 2013.

[8] K. WazedNafi et al., "An Advanced Door Lock Security System using Palmtop Recognition System", International Journal of Computer Applications, Vol. 56, No. 17, October 2012.

[9] A. Aditya Shankar et al., "Finger Print Based Door Locking System", International Journal of Engineering and Computer Science, Vol. 4, No. 3, pp. 10810-10814, March 2015.

[10] J. C. Augusto and C. D. Nugent, "Smart homes can be smarter," in Designing Smart Homes. Springer, pp. 1-15, 2006.

[11] D. Cook and S. Das, Smart environments: technology, protocols and applications, John Wiley \& Sons, Vol. 43, 2004.

[12] S. Vig and S. Vig, "Smart doorbell security system and method to identify visitors," Aug. 23 2010, US Patent App. 12/861,427.

[13] G. Demiris, B. K. Hensel et al., "Technologies for an aging society: a systematic review of smart home applications," Yearb Med Inform, Vol. 3, pp. 33-40, 2008.

[14] D.M. Han and J.-H. Lim, "Design and implementation of smart home energy management systems based on zigbee," Consumer Electronics, IEEE Transactions, Vol. 56, No. 3, pp. 1417-1425, 2010. 